Article

\title{
The Dynamic Value of China's High-Tech Zones: Direct and Indirect Influence on Urban Ecological Innovation
}

\author{
Siying Yang ${ }^{1,2}\left(\right.$, Wei Liu ${ }^{3, *}$ and Zhe Zhang ${ }^{4}$ \\ 1 Centre for China Public Sector Economy Research, Jilin University, Changchun 130015, China; \\ yangsy@jlu.edu.cn \\ 2 Economics School, Jilin University, Changchun 130015, China \\ 3 Business School, Qingdao University, Qingdao 266071, China \\ 4 Sydney School of Architecture, Design and Planning, The University of Sydney, Sydney 2006, Australia; \\ zzha2848@uni.sydney.edu.au \\ * Correspondence: wei.liu@qdu.edu.cn
}

check for

updates

Citation: Yang, S.; Liu, W.; Zhang, Z.

The Dynamic Value of China's

High-Tech Zones: Direct and Indirect

Influence on Urban Ecological

Innovation. Land 2022, 11, 59.

https://doi.org/10.3390/

land11010059

Academic Editors: Shaojian Wang,

Yu Yang, Yingcheng Li, Shuai Shao

and Rui Xie

Received: 12 December 2021

Accepted: 28 December 2021

Published: 1 January 2022

Publisher's Note: MDPI stays neutral with regard to jurisdictional claims in published maps and institutional affiliations.

Copyright: (C) 2022 by the authors. Licensee MDPI, Basel, Switzerland. This article is an open access article distributed under the terms and conditions of the Creative Commons Attribution (CC BY) license (https:// creativecommons.org/licenses/by/ $4.0 /)$.

\begin{abstract}
China's High-tech Industrial Development Zones (HTZ) are industrial agglomeration areas established by the local government to foster economic innovation. As springboards for cities to implement innovation-driven development strategies, HTZs have significant spillover and driving effects on urban ecological innovation. Based on panel data taken from 215 cities between 2003 and 2016, this paper empirically analyzes the impact of HTZ construction and its mechanisms as they pertain to urban ecological innovation. This analysis is framed by the double difference model and the intermediary effect model. It found that HTZ construction can effectively enhance urban ecological innovation, and formidably promote ecological innovation in central and eastern cities, as well as cities with superior scientific and educational resources. The intermediary mechanism analysis revealed that HTZs result in a policy depression effect, which may promote the agglomeration of urban innovation factors (including high-quality talents and investment), thereby bolstering urban ecological innovation. Moreover, HTZs' investment agglomeration effect is primarily responsible for driving urban ecological innovation. Indeed, the HTZ construction may not only promote the local ecological innovation, but also have a significant spillover effect on the ecological innovation activities of other cities in the province.
\end{abstract}

Keywords: national high-tech zone; ecological innovation; factor agglomeration; spillover effect; siphoning effect

\section{Introduction}

China is the most populous country in the world: facing the tremendous pressures of economic growth while bearing the heavy burden of the ecological environment. The nation's eco-environmental problems became particularly prominent in 2014 . Of the 161 cities monitored according to the new air quality standards issued in 2012, the annual average compliance rate is less than $10 \%$. Precipitation monitoring data show that the proportion of acid rain in cities has reached $29.8 \%$, with an average frequency of $17.4 \%$. For governments to manage the ecological environment, it is necessary to accelerate the promotion of scientific and technological innovation [1,2]. Yet, the former bears the consequences of the latter. For example, substituting chemical fertilizer with traditional farm manure has improved agricultural production efficiency, but it has also resulted in land and water pollution. Moreover, automobiles and other modern means of transportation are more efficient than their archaic predecessors, but they have also generated noise, air, and other forms of pollution. For this reason, Brawn and Wield (1994) presented the concept of green technology, which consistently advocates technological advancement activities with both ecological and economic benefits [3]. Subsequently, James (1997) introduced the concept 
of ecological innovation to summarize new products or processes that benefit the ecological environment and potentially create economic value [4]. The tenets of ecological advancement are low pollution, sustainability, and high efficiency-which may promote economic growth while ensuring ecological benefit. Thus, this approach is significant in its ability to promote the development of China's economy in ways that are both refined and sustainable [5].

Scientific and technological innovation requires a solid industrial foundation and a good environment. Moreover, industrial agglomeration is of major importance to innovation activities, which boost the level of innovation in many ways, e.g., by enhancing knowledge spillover [6]. It is precisely due to the agglomeration economy's characteristic of increasing scale returns that there are different types of agglomeration areas (e.g., industrial and innovation clusters) in countries all over the world. The development of Chinese innovation clusters differs to the spontaneous agglomeration regulated by the market mechanism in that it bears the distinct characteristics of government guidance [7]. For example, Beijing Zhongguancun Science and Technology Park is China's first national HTZ. It is also the first independent national innovation demonstration zone and scientific and technological innovation agglomeration area to be promoted by national policies. In 1988, the State Council approved the establishment of the Beijing High-tech Industry Development Experimental Zone (renamed Zhongguancun Science and Technology Park in 1999), which was uniformly planned and managed by the Beijing Municipal Government. High-tech parks planned and overseen by central or local governments continue to emerge and become a mode of agglomeration economic development with Chinese characteristics.

Reasonable economic zone planning is an important safeguard in the urban economic development promotion process. Thus, a series of studies have examined the innovation ability and level of HTZs and science and technology parks. For instance, both Goetz and Ru-pasingha (2002) and Corrocher et al. (2019) found that firms in science and technology parks perform better in the areas of innovation output and efficiency due to the favorable conditions of collaborative innovation among innovation subjects, knowledge spillover, and scale economy [8,9]. Xie et al. (2018) found that HTZs are important policy tools and vehicles for the government to both engage in and lead the development of the local innovative economy [10]. Another reason that HTZs/science and technology parks foster advancement is the fact that park enterprises often work closely with research and development (R\&D) universities and research institutions [11]. The greater the institutions' participation in the park construction, the better the parks' innovation performance will be [12-14]. High-tech enterprises, especially high-quality foreign investment agglomeration, are also an important reason for the parks' improved innovation level [15-17].

Unlike the aforementioned researchers, Bai et al. (2015) examined the innovation performance of national HTZs in different Chinese provinces and found that their R\&D and production departments were inefficient [18]. Moreover, the disconnect between the departments lead to low operational efficiency and serious waste of innovation resources. For their part, Yang and Guo (2020) observed that while the innovative ability of local HTZs is gradually improving, it is still at a relatively low level overall [19]. Cao (2004) investigated the reasons for this developmental lag, which included the path dependence of development model, the innovation system's protracted construction, lack of innovation incentives for enterprises, unclear definition of property rights, etc. [20].

Notably, the former research presents certain problems: (1) it regards HTZ as a regional concept, and (2) it analyzes and compares the zones' innovation capability and performance using the empirical analysis method. There are few studies on the dynamic characteristics of urban ecological innovation pre- and post-HTZ. Still, as previously stated, HTZs are innovation agglomeration areas under governmental guidance, and an important policy method and tool for the state to promote scientific and technological advancement. Accordingly, this is not only a regional concept, but a policy concept, too. Notably, there remain differences in the existing literature on the level of scientific and technological innovation in HTZs. Moreover, research on ecological innovation's impact on HTZ establishment is 
lacking. Thus, this paper will examine the impact of China's national HTZ construction on the urban ecological innovation level, as well as its mechanisms.

This paper differs significantly from the previous literature in that it introduces the concept of the national HTZ as a policy concept into the empirical analysis. Moreover, it examines the impact of HTZ construction on urban ecological innovation and its heterogeneity using the double difference model. It found that establishing national HTZs promotes urban ecological innovation. Moreover, HTZs are more impactful in promoting ecological innovation activities in core cities, cities in eastern regions, and cities with high-quality scientific and educational resources than they are in peripheral cities, cities in central and western regions and cities with sub-par scientific and educational resources. This discovery expands the research on national HTZs' innovation effect and affirms the government's crucial role in forming and developing innovation agglomeration areas as well as regional ecological advancement. Furthermore, it provides a new model for the economic development through in other countries: one in which the government promotes and leads the construction of agglomeration areas.

While it is important to investigate the impact of national HTZ construction on urban ecological innovation, investigating their internal mechanisms can provide the reference value needed to enhance both theory and policy making. The study found that national HTZ construction promote the agglomeration of high-quality talents and boost social investment into fixed assets, thus bolstering the level of urban ecological innovation. It is evident that HTZs' factor agglomeration effect is a key component in process of promoting urban ecological innovation, and the intermediary effect accounts for about $62.38 \%$ of the total effect. This conclusion illuminates the process by which HTZ construction promotes urban ecological innovation and provides more detailed evidence about, and insight into, the ecological innovation effects.

Furthermore, due to the high mobility of innovation elements and the strong externalities of innovation activities, implementing innovation policies in a given region may significantly impact innovation in surrounding cities. This externality is either a spillover effect or a siphon effect. In China, a country of "political centralization and economic decentralization", the unique political system ensures that HTZ policy has a dissimilar impact on different surrounding cities. Notably, the existing research does not sufficiently engage the external characteristics of national HTZs. Accordingly, this study finds that spatial heterogeneity - "cooperation within the province and competition outside the province"is characteristic of HTZs' ecological innovation effect. HTZ development has a significant spatial spillover effect on other cities within the province but has a notable siphoning effect on neighboring cities outside the province. This is mainly due to the competitive interregional relationship between provincial governments under China's special centralized political system. Conversely, cities in the province have formed a cooperative relationship under the planning guidance of the same provincial government.

From this point, the paper is structured as follows. Part two introduces the China's national HTZ development, and analyzes the mechanisms of their impact on urban ecological innovation. Finally, it presents the research hypotheses. Part three introduces the methods and data used in the empirical analysis, while part four is comprised of the results and discussion sections. The last part summarizes the main conclusions of this study, considers its limitations, and discusses avenues for further research.

\section{Theory and Hypotheses}

\subsection{The Impact of HTZ Construction on Urban Ecological Innovation}

The HTZ is a designated area in the city that serves to develop high-tech industries. It is an important tool to promote the commercialization, industrialization, and internationalization of China's high-tech achievements [21]. Since the approval of Beijing Zhongguancun Science and Technology Park in 1988, the construction of China's National HTZ policy has continued to evolve for over 30 years. Moreover, it has progressed in the way of high-tech industry cluster development with Chinese characteristics. With a unique developmental 
model, HTZs have gradually become an important part of the local urban innovation system [22]. The Zhongguancun Science and Technology Park has leading industries which span six fields, including electronic information, new materials, and biomedicine. In 1991 and 1992, the state approved the establishment of more than 50 national HTZs in Tianjin and other cities, and each HTZ has its own unique leading industries. Over the next decade, this growth rate slowed, followed by a trend of ongoing acceleration that began in 2010 . Indeed, the state greenlit HTZs in 25 cities, including Yingkou and Kunshan, that same year. From 2011 to 2018, the number of national HTZs increased by 85, and currently stands at 169 (including Suzhou Industrial Park). Notably, HTZ development is not only reflected by their numerical increase, but also their major economic volume. Establishing these zones provides a strong momentum for China's economic growth. For example, in 2019, the HTZs produced a GDP of 12.2 trillion yuan (accounting for $12.3 \%$ of the national GDP), and paid taxes and fees of 1.9 trillion yuan (accounting for $11.8 \%$ of tax revenues).

Notably, HTZs have two key functions that enable them to enhance ecological innovation in parks: leading innovation direction and gathering innovation elements. Both these functions can maximize the scale economy effect of ecological innovation activities. On the one hand, government departments embrace the advantages of total information collection and processing, assess the frontier technology of ecological innovation more accurately, and will encourage enterprises in HTZs to implement this innovation through strategic guidance. In 1991, for example, the state promulgated the conditions and measures for recognizing high-tech enterprises in HTZs. According to the modern global context of science and technology development, this policy defines the scope of high-tech, which includes: material science and new material technology, energy science and new energy, high-efficiency energy-saving technology, ecological science and environmental protection technology, and other ecological innovation technologies. These policies engender detailed plans for developing ecological innovation frontier areas. These areas, in turn, can stabilize the confidence of innovation subjects and investors. Moreover, they may prompt social advancement resources to gather therein by using subsidies and innovation incentives-which can effectively promote the ecological innovation of HTZs.

On the other hand, the government will establish a policy depression in HTZs through subsidies, tax incentives and other measures that attract high-tech enterprises and highquality R\&D talents. This will be supplemented by a strict ecological threshold, and environmental regulation policies, so as to improve HTZs' ecological innovation level. For example, in 1991, the state promulgated interim provisions on several HTZ policies and provisions on HTZ tax policy. The government also gave corresponding policies to the high-tech enterprises engaged in frontier ecological innovation in the park. These preferential policies accounted for import and export goods licensing, tariffs, capital credit, price protection, tax preference, etc. The state subsequently revised relevant policies and regulations in 2000, 2006, and at many other points. In this way, it constantly optimized policy programs, while supporting and leading scientific and technological advancement activities, including ecological innovation. In addition, the newly issued document, "Several opinions of the State Council on promoting the high-quality development of national high-tech industrial development zones" notes the need to: (1) promote the construction of ecological industrial demonstration parks in HTZs, (2) actively encourage all kinds of green and innovative resources to participate in the construction of HTZs, (3) strictly control the entry of enterprises with high pollution, high energy consumption, and high emissions, and (4) create green and intelligent science and technology parks.

Beyond potentially promoting the ecological innovation level of HTZs, a series of preferential policies may exact important spillover and driving effects on the ecological innovation of the city where the park is located [23]. The innovation network of HTZs extends beyond the park's interior to the entire city and even further, thereby exacting a radiation driving effect on urban ecological innovation [21]. There will be various innovation-related connections between the enterprises in the HTZs and the enterprises, universities, or scientific research institutions in the city where they are located. This kind 
of connection may use personnel flow or products and raw materials as the carrier, or it may entail the direct transfer of ecological technology. Due to HTZs limited special capacity, the green industry and innovation elements associated with the industries in HTZs are not just concentrated in the zones themselves, but distributed around them. Spanning the entire city, they are interrelated and drive each other to increase the urban ecological innovation level. Furthermore, constructing HTZs both accelerates the agglomeration of high-tech industries and forms a huge gap between high-tech and ecological knowledge. Indeed, the formidable demand for knowledge will force science and education resources, such as universities and scientific research institutes, to integrate and agglomerate around the HTZ. This will strengthen the cooperation toward ecological advancement both in and outside the zone. Enterprises within HTZs strengthen cooperation with innovation subjects without-or transfer green technology-forming an innovation network that covers the whole city. As ecological technology inside spreads beyond the HTZ, and urban ecological advancement is promoted [24].

Based on the above analysis, this paper proposes the following hypothesis.

Hypothesis 1. Constructing HTZs will promote the urban ecological innovation level.

\subsection{The Heterogeneity of Science, Education Resources, and Regions}

Cities have differ in economic scale, ability to gather innovation factors, innovation resource allocation efficiency, ability to develop sustainable environments, capacity for central policy acquisition, and implementation ability. These differences may also foster the HTZ construction's disparate impact on ecological innovation. From the perspective of urban function, the central city is often the focus and forerunner of national or regional economic development strategy. It also has a high level of scientific and technological innovation and can be deemed an ecological environment. For the sake of brevity, this paper defines the municipality directly under the central government, the provincial capital city, and the sub provincial city as the central city. Compared to peripheral cities (all that do not fall under the "central city" definition previously stated), central cities have a strong capacity to gather innovative elements, and promote urban ecological advancement. This is by virtue of the scale, policy, and innovation elements of their economic development [25]. The geographical advantages of the central city are further strengthened after the HTZ is established. This helps to attract more innovation resources and creates an industrial and factor context that is conducive to ecological innovation.

In peripheral cities, however, science and education resources are relatively poor, and scientific and technological innovation starts comparatively late. Beyond starting late, it is still production-oriented, and the market value of scientific and technological innovation is emphasized while its ecological value is ignored. Thus, constructing HTZs in peripheral cities may generate a significantly weaker ecological innovation effect than it does in central ones.

From the perspective of regional differences, Eastern China has a high level of openness to the world, rich science and education resources, a good industrial foundation, and ideal infrastructure. The gaps that other regions face regarding capital, talent, and infrastructure is small, thus urban innovation is relatively high. In other words, a solid economic, scientific, and technological environment enables Eastern Chinese cities to engage in ecological innovation. At this time, constructing HTZs with a series of ecological and environmental protection requirements and thresholds will encourage enterprises to engage in ecological innovation to enjoy the preferential policies that come with HTZ entry.

In Central and Western China, economic development is lagging, and the scientific and technological foundations of ecological innovation are relatively weak. Though establishing an HTZ may promote urban innovation to an extent, these regions pay more attention to economic scale: prioritizing the economic benefits of scientific and technological advancement and ignoring ecological benefits. Thus, the impact that HTZ establishment 
exacts upon ecological innovation is significantly stronger in Eastern China than Central and Western.

It is also necessary to consider differences in science and education resources, as their quality directly determines the standard and level of urban innovation. Disparities in these areas may also contribute to HTZs' differential impact on the urban ecological innovation level. Cities with superior resources constitute an environment conducive to scientific and technological innovation. Accordingly, HTZ construction may integrate the highquality innovation resources of cities, form an efficient collaborative innovation system, and play a more significant role in promoting urban ecological innovation. Conversely, cities with relatively low quality resources are, of course, less conducive. It is possible for HTZ construction to leverage the potential of urban innovation and somewhat improve its vitality. However, due to the resource shortage, HTZ construction has a marginal impact on urban ecological innovation.

Based on the above analysis, three hypotheses are proposed.

Hypothesis 2a. The impact of HTZ construction on urban ecological innovation is characterized by urban hierarchy heterogeneity, meaning ecological innovation promotion is significantly stronger in central cities than peripheral ones.

Hypothesis $\mathbf{2 b}$. The impact of HTZ construction on urban ecological innovation is characterized by heterogenous science and education resources, meaning ecological innovation promotion is significantly stronger in cities with high quality science and education resources than those with low quality ones.

Hypothesis 2c. The impact of HTZ construction on urban ecological innovation is characterized by regional heterogeneity, meaning urban ecological innovation promotion is significantly stronger in Eastern Chinese cities than in Central and Western ones.

\subsection{The Role of Agglomeration Ability of Urban Innovation Elements}

Unlike the spontaneous agglomeration under the market mechanism seen in most countries, China's HTZs are traction agglomeration zones spearheaded by government policies and local development strategies. The combination of various preferential policies makes the HTZ a policy depression: attracting high-quality innovative talents and innovative capital [26]. On the one hand, the innovation activities of enterprises in the agglomeration zone benefit from special development policies (e.g., low land price and preferential taxes that are lower than those in the external THZs). These policies reduce the burden that enterprise operating costs bear on the innovation funds of enterprises in HTZs. They also guarantee capital supply for enterprises' ecological innovation activities, and foster enterprise ecological innovation itself. Entering HTZs need to meet the high ecological threshold, as this will force enterprises to actively implement ecological innovation activities.

On the other hand, HTZs' efficient administrative service and their policy guidance on scientific and technological innovation will encourage high-tech enterprises to gather in the park, thus driving the ecological innovation of HTZs and cities [27]. For example, to protect the legitimate innovation income of enterprises, HTZs encourage them to apply for, and maintain, patents. They also reinforce the protection of enterprises' intellectual property rights. To encourage enterprises to participate in collaborative innovation, the HTZ management department has bolstered subsidies and support for the joint construction of an R\&D platform by schools and enterprises. In 2001, the Ministry of Science and Technology proposed that HTZs should realize "secondary entrepreneurship" and strengthen the guidance and policy support for connotative development ideas [23]. This was done to steer HTZs from an investment-driven developmental mode to an innovation-driven one. A series of policies and measures will have a significant role in promoting ecological innovation and other innovation activities. Moreover, the ideal HTZ infrastructure creates convenient 
conditions for enterprises to implement ecological innovation activities. These, in turn, may attract quality foreign investment capital and improve the ecological innovation level of HTZs.

Urban ecological innovation is inseparable from innovative talents and entrepreneurs. People, especially superior talents, are the most critical and active components of ecological innovation. Notably, HTZs also issue a series of preferential policies for talents, which can stimulate and protect entrepreneurship and attract people with innovative and entrepreneurial skills. For example, "measures to improve innovation ability and optimize innovation environment" (the latest such document issued by Foshan HTZ), awards high subsidies to help remarkable innovative talents build a talent gathering highland. Financial subsidies will be given to doctoral or master's degrees holders who secure employment in the HTZ. Doctoral research start-up projects and outstanding youth research projects will be rolled out to encourage young talents to engage in innovation and R\&D work. Furthermore, other HTZs provide innovative talents with various subsidies and tax-related preferential policies. For example, Changsha HTZ provides an interest subsidy that skilled workers' may use on their mortgage. Jining HTZ issues a living subsidy of up to 500,000 yuan to enterprises that employ high-level foreign experts. Beijing Zhongguancun HTZ implements an evaluation policy that aims to attract highly skilled foreign nationals and help them secure permanent residence in China. These strategies create a policy environment that ensures that HTZs may secure high-quality talents, thus producing the human capital necessary for urban ecological innovation.

Based on this analysis, we propose the following hypothesis.

Hypothesis 3. HTZ construction can strengthen the agglomeration ability of urban innovation elements, promote the agglomeration of urban investment factors and talent elements, thereby enhancing urban ecological innovation.

\subsection{The Siphoning Effect of HTZ Construction}

The agglomeration of urban innovation elements is not a Pareto improvement process. While HTZs are constructed and innovation resources gathered, innovation elements in neighboring areas may be lost. Generally, an HTZ may attract the innovation elements of surrounding and provincial cities through low land prices and preferential tax policies outside the HTZ city. While improving the ecological advancement of HTZ cities, this siphons the ecological innovation of surrounding and provincial cities while stifling their progress. Based on this, we propose the following hypothesis.

Hypothesis 4. HTZ construction will not only improve the level of urban ecological innovation, but also siphon the ecological innovation activities of surrounding cities and inhibit their ecological innovation.

\section{Methodology}

\subsection{Estimation Models}

China's 169 HTZs span 158 cities. HTZs are not only located in the eastern regions of China with high development levels, but also in the central and western regions with low development levels, representing that the selection of policy group samples has certain random characteristics. With that in mind, this paper views HTZ establishment as a quasinatural experiment to assess the impact of HTZ construction on urban ecological innovation. Cities that instituted national HTZs from 2003 to 2016 constitute the experimental group, and those without them are the control group. Since China's HTZ establishment expands year by year, the traditional double difference model is limited in its ability to observe the effect of policies implemented at just one point in time. Thus, this paper uses the practices 
of Autor (2003) and Bertrand and Mullainathan (2003) as a reference to build a multiperiod double difference model $[28,29]$, as shown in Formula (1):

$$
{ }_{i n n o} o_{i t}=\alpha_{0}+\alpha_{1} H T Z_{i t}+\sum \alpha_{j} X_{j i t}+u+t+\varepsilon_{i t}
$$

In the above formula, $i n n o_{i t}$ represents the ecological innovation level of city $i$ in year t. HTZ $i t$ is a dummy variable, which indicates whether city $i$ has established an HTZ in year $t$, which is the core explanatory variable of this paper. $X_{j}$ represents the set of other control variables that affect urban ecological innovation, including the level of openness, human capital, and so on. Moreover, $u$ and $t$ represent individual dummy variables and year dummy variables, respectively, to control for time and individual fixed effects, while $\varepsilon$ is random error term.

To test Hypotheses 2.1-2.3-that is, to investigate the differential characteristics of the impact of HTZ construction on ecological innovation in different cities- this paper further constructs a regulatory effect model, as shown in Formula (2):

$$
\text { inno }_{i t}=\alpha_{0}+\alpha_{1} H T Z_{i t}+\alpha_{2} H T Z_{i t} \times H+\sum \alpha_{j} X_{j i t}+u+t+\varepsilon_{i t}
$$

Here, $\mathrm{H}$ is the virtual variable of city characteristics, including the virtual variable of city hierarchy, the virtual variable of urban science and technology resource quality, and the virtual variable of urban location. $\alpha_{2}$ reflects the difference in the impact of HTZ construction on urban ecological innovation under different urban characteristics.

To analyze the mechanisms of HTZ construction's influence on urban ecological innovation - that is, to test Hypothesis 3-we set up the regression models shown in Formulas (3) and (4) using Baron and Kenny (1986) as a reference, and formed an intermediary effect model with Formula (1) [30].

$$
\begin{gathered}
M_{i t}=\beta_{0}+\beta_{1} H_{T Z} Z_{i t}+\sum \beta_{j} X_{j i t}+u+t+\varepsilon_{i t} \\
\text { inno }_{i t}=\phi_{0}+\phi_{1} H T Z_{i t}+\phi_{2} M_{i t}+\sum \phi_{j} X_{j i t}+u+t+\varepsilon_{i t}
\end{gathered}
$$

In the two formulas above, $M$ represents the intermediary variable, namely, the talent concentration and investment concentration levels. Based on the significance of $\alpha_{1}$ in the regression model shown in Formula (1), the regression models in Equations (3) and (4) are further estimated to test the impact of HTZ construction on innovation factor agglomeration and the latter's impact on ecological innovation. If $\beta_{1}$ and $\phi_{2}$ are simultaneously significant, HTZ construction will influence urban ecological innovation by affecting the agglomeration of innovation factors. Its intermediary effect is $\beta_{1} \times \phi_{2}$, accounting for the total effect of $\beta_{1} \times \phi_{2} / \alpha_{1}$. If $\phi_{1}$ in Formula (4) is still significant at this time, then $M$ is a partial mediation variable, and HTZ construction will also affect urban ecological innovation, directly or indirectly (through other mechanisms). If $\phi_{1}$ is no longer significant at this time, then M is a complete intermediary variable; HTZ construction can only affect urban ecological innovation by influencing $M$ variables, and there is no direct impact nor alternative mechanism.

The preferential policies within HTZs have an agglomeration effect on innovative enterprises. This raises the question of whether HTZs' policy depression effect will plunder and siphon the innovative resources and elements in the surrounding areas. To answer this question, we employed the research methods of Delgado and Florax (2015) and Paliska (2018), to expand upon a Spatial Difference-in-Differences model [31,32], as shown in Formula (5):

$$
\text { inno }_{i t}=\alpha_{0}+\alpha_{1} H T Z_{i t}+\alpha_{2} w H T Z_{i t}+\sum \alpha_{j} X_{j i t}+u+t+\varepsilon_{i t}
$$

Here, $\mathrm{W}$ represents the spatial weight matrix. Notably, this paper presents three kinds of weight matrices. The intra-provincial correlation weight matrix assumes that the influence of the HTZ policy is limited to the HTZ city and other cities in the same province. 
Using this tool, we can investigate the externalities of the impact of HTZ construction on the ecological innovation activities of other cities in the same province. The correlation weight matrix of neighboring cities outside the province assumes that HTZs' influence is limited to the HTZ city and surrounding cities outside the province. From this stance, we can examine the externalities of the impact of HTZ construction on the ecological innovation activities of neighboring cities in other provinces. Finally, the correlation weight matrix between the HTZ province and neighboring cities in other provinces assumes that the influence HTZ policy spans the HTZ city and other cities in that province, as well as neighboring cities in other provinces.

\subsection{Variable Measurements and Data}

Existing research mostly measures ecological innovation level from the micro perspective. The enterprise data is mainly obtained by issuing questionnaires [33]. Whether the enterprise conducts green technology $R \& D$ or has green infrastructure investment and other conditions is what often determines the virtual variable $[5,34]$. Some literature embraces measures of ecological innovation using the types of enterprise ecological innovation and the level of innovation investment. However, these methods are obviously not suitable for the study of ecological innovation at regional level. Notably, Kesidou and Wu (2020) measure the provincial ecological innovation level by the number of green technology patents obtained by enterprises [35]. Using this approach as a reference, this paper uses a ratio (the number of green invention patents applied for by economic entities in cities to the urban population) as the measure index for urban ecological innovation level.

Evidently, HTZ construction is the core explanatory variable of this paper, which employs virtual variables. We define the year in which the HTZ is established, and its subsequent years, as 1 , and the rest as 0 . Since some HTZs were established relatively late in some years, the impact on urban ecological innovation was weak. To this end, this paper takes the following approach: if the HTZ was instituted between January and September, the current year is deemed the starting year for HTZ construction in the city. If it was instituted between October and December, the following year is considered the starting point. In addition to this, researchers created a group dummy variable (treat). The cities that HTZ construction between 2003 and 2016 were assigned a value of 1 (the experimental group), and those that did not institute HTZs during that period were assigned 0 (the control group).

Drawing lessons from previous studies, this paper also controls for other variables that affect urban ecological innovation, with consideration given to the degree of openness in the environment, human capital conditions, economic environment, and policy conditions of urban innovation activities [36]. It mainly includes: foreign direct investment (fdi), measured by the proportion of urban foreign direct investment to the regional gross domestic product [37]; human capital level (hum), measured by the proportion of students in colleges and universities to the total urban population [38]; the level of economic development (pgdp), measured by the per capita real regional gross domestic product (GDP) in 2003, which serves as the base period to eliminate the price factor; the level of financial development (fin), measured by the ratio of financial institutions' balance of deposits and loans to the local GDP at the end of the year and in each city; industrial structure (ind), measured by the proportion of the added value of non-agricultural industries to the regional gross domestic product; government innovation policy (g_tec), measured by the proportion of science and technical expenditure in the government financial expenditure; the level of urban entrepreneurship (entre), measured by the proportion of urban, private, and self-employed people to the urban resident population.

Since HTZ construction began in 1988, and new HTZs were constructed in 2017 and 2018, this paper excludes samples that fall beyond the period in question (2003-2016) to eliminate their impact on the empirical results. The green patent data are obtained by eliminating non-green patent data per the green patent international patent classification code. They were then added to the city when we searched the national patent application 
data on the State Intellectual Property Office website. The rest of the data comes from the EPS data platform. The statistical characteristics of each index and its correlation coefficient with the level of urban innovation are shown in Table 1. It is evident that the correlation coefficient between HTZ construction and urban ecological innovation level is significantly positive at the level of $1 \%$, which preliminarily shows that HTZ construction plays a role in promoting ecological innovation. Of course, this conclusion requires further testing.

Table 1. Data characteristics.

\begin{tabular}{ccccccc}
\hline Variables & $\begin{array}{c}\text { Sample } \\
\text { Size }\end{array}$ & Mean Value & $\begin{array}{c}\text { Standard } \\
\text { Deviation }\end{array}$ & $\begin{array}{c}\text { Minimum } \\
\text { Value }\end{array}$ & $\begin{array}{c}\text { Maximum } \\
\text { Value }\end{array}$ & Correlation \\
\hline eco-innovation & 3007 & 0.0860 & 0.2508 & 0.0000 & 5.8308 & 1 \\
HTZ & 3010 & 0.1093 & 0.3121 & 0.0000 & 1.0000 & $0.3614^{*}$ \\
treat & 3010 & 0.3767 & 0.4847 & 0.0000 & 1.0000 & $0.2089 *$ \\
fdi & 3008 & 0.0242 & 0.0282 & 0.0000 & 0.4540 & $0.1557^{*}$ \\
hum & 2989 & 0.0090 & 0.0114 & 0.0000 & 0.1205 & $0.2889 *$ \\
pgdp & 3007 & 8.1857 & 0.7244 & 0.0000 & 11.0047 & $-0.0473 *$ \\
fin & 3008 & 1.8451 & 0.6817 & 0.5081 & 8.7774 & $0.1826^{*}$ \\
ind & 3010 & 0.8355 & 0.0911 & 0.0000 & 0.9967 & $0.2839 *$ \\
gov_tec & 3010 & 0.0093 & 0.0104 & 0.0000 & 0.2068 & $0.4870 *$ \\
entre & 3010 & 0.0778 & 0.0692 & 0.0000 & 1.2411 & $0.6036^{*}$ \\
\hline Note: * $p<0.1$ & & & & & &
\end{tabular}

\section{Results}

\subsection{Benchmark Regression}

To test HTZ construction's impact on the level of ecological innovation, this paper first estimates Formula (1), and results are shown in Table 2. Regression (1) only employs $\mathrm{HTZ}$ as the explanatory variable, and its coefficient is significantly positive at the level of $1 \%$ : indicating that urban ecological innovation has improved post-HTZ construction. This may be due any of these three reasons. First, the time trend effect, in which the urban ecological innovation level continues to improve as time passes. Second, the cities approved to construct HTZ themselves have a higher level of ecological innovation. Third, HTZs have significantly improved the level of urban ecological innovation. Regression (2) further controls the time fixed effect to eliminate the time trend effect's influence on the estimated results, and the HTZ regression coefficient is still significantly positive. Regression (3) adds the group virtual variable, and it is evident that its regression coefficient is significantly positive. This shows that cities with HTZs have a higher level of ecological innovation than those without, thereby confirming the second potential reason stated earlier.

Table 2. Benchmark regression.

\begin{tabular}{|c|c|c|c|c|c|c|c|}
\hline & (1) & (2) & (3) & (4) & (5) & (6) & (7) \\
\hline Variables & inno & inno & inno & inno & inno & inno & inno \\
\hline $\begin{array}{l}\text { HTZ } \\
\text { treat }\end{array}$ & $\begin{array}{c}0.2903 * * * \\
(0.0137)\end{array}$ & $\begin{array}{c}0.2144^{* * *} \\
(0.0147)\end{array}$ & $\begin{array}{c}0.1624^{* * *} \\
(0.0168) \\
0.0611^{* * *} \\
(0.0098)\end{array}$ & $\begin{array}{c}0.1541^{* * *} \\
(0.0145)\end{array}$ & $\begin{array}{c}0.0933^{* * *} \\
(0.0131)\end{array}$ & $\begin{array}{c}0.0969 * * * \\
(0.0146)\end{array}$ & $\begin{array}{c}0.1201 * * * \\
(0.0174)\end{array}$ \\
\hline $\begin{array}{l}\text { Control } \\
\text { variable }\end{array}$ & $\mathrm{N}$ & $\mathrm{N}$ & $\mathrm{N}$ & $\mathrm{N}$ & $\mathrm{Y}$ & $\mathrm{Y}$ & $\mathrm{Y}$ \\
\hline Time effect & $\mathrm{N}$ & $\mathrm{Y}$ & $\mathrm{Y}$ & $\mathrm{Y}$ & $\mathrm{Y}$ & $\mathrm{Y}$ & $\mathrm{Y}$ \\
\hline $\begin{array}{c}\text { Individual } \\
\text { effect }\end{array}$ & $\mathrm{N}$ & $\mathrm{N}$ & $\mathrm{N}$ & $\mathrm{Y}$ & $\mathrm{Y}$ & $\mathrm{Y}$ & $\mathrm{Y}$ \\
\hline Constant & $\begin{array}{c}0.0543 * * * \\
(0.0045)\end{array}$ & $\begin{array}{c}0.0084 \\
(0.0156)\end{array}$ & $\begin{array}{l}-0.0149 \\
(0.0160)\end{array}$ & $\begin{array}{c}0.0077 \\
(0.0124)\end{array}$ & $\begin{array}{c}0.8161^{* * *} \\
(0.1489)\end{array}$ & $\begin{array}{c}0.8536^{* * *} \\
(0.1568)\end{array}$ & $\begin{array}{c}0.9666 * * * \\
(0.1749)\end{array}$ \\
\hline Observations & 3007 & 3007 & 3007 & 3007 & 2981 & 2769 & 2554 \\
\hline R-squared & 0.1306 & 0.1811 & 0.1916 & 0.2279 & 0.4173 & 0.4240 & 0.3695 \\
\hline $\begin{array}{c}\text { Number of } \\
\text { cities }\end{array}$ & 215 & 215 & 215 & 215 & 215 & 215 & 215 \\
\hline
\end{tabular}

Note: ${ }^{* *} p<0.01,{ }^{* *} p<0.05$, and ${ }^{*} p<0.1$. Standard errors in parentheses. 
After controlling the time trend effect and the ecological innovation advantage of the HTZ city, the regression coefficient of the HTZ policy virtual variable is still significantly positive. To eliminate the influence of urban individuals' characteristics on the estimated results, Regression (4) further controls the fixed effect of urban individuals, and Regression (5) adds other control variables that affect the level of ecological innovation. The regression results show that the coefficient of the HTZ policy virtual variables has always been significantly positive at the level of $1 \%$, indicating that HTZ construction has significantly improved urban ecological innovation. Furthermore, the approval of green invention patent applications is often protracted, so Regressions (6) and (7) treat all explanatory variables with a lag one year and two years, respectively. This may also help avoid the endogenous problems caused by reverse causality. The results still demonstrate that the HTZ regression coefficient remains significantly positive. Thus, the results indicate that HTZ construction can significantly promote urban ecological innovation, and Hypothesis 1 has been confirmed.

Our results are similar to Zheng and Li (2020) and Wang and Feng (2021), but not exactly the same $[17,39]$. Zheng and Li (2020) confirmed the role of HTZs in promoting technological innovation from the perspective of enterprise agglomeration and industryuniversity-research cooperation [17]; Wang and Feng (2021) found that HTZs play an important role in regional economic growth and emission reduction [39]. However, neither of them involves the research on the ecological innovation effect of HTZ construction. Our results are a supplement to this research gap. The reason why the construction of HTZs can promote ecological innovation may be based on the factor agglomeration effect of high-tech zones, that is, the construction of HTZs may attract investment with green and innovative attributes and the agglomeration of innovative human capital, thus promoting ecological innovation. We will test these mechanisms later.

\subsection{Robustness Test}

First, we use alternative measures of explained variables for robustness test. Green patents include invention patents and utility model patents. Here, the ratio of the sum of the two types of green patent applications to the total urban population is used as an alternative index of urban ecological innovation level and estimated using Formula (1). The results are shown in Regression (1) in Table 3. Evidently, the regression coefficient of HTZ virtual variables is also positive under the significance level of $1 \%$. This indicates that the HTZ construction has improved the level of urban ecological innovation, which is consistent with the above conclusion.

Second, this paper uses the propensity score matching method to match samples, then re-estimates them based on the matched ones. In 1991, the State Council issued a circular, the Approval of National High-tech Industrial Development Zones and Relevant Policies and Regulations, which clearly stated that HTZs should be constructed in both large and medium-sized cities and coastal areas home to intensive information and technology resources. Accordingly, it is evident that selecting China's HTZ sites is not an entirely random process, though there are certain selective deviations in the establishment procedure. Thus, this paper again uses the propensity score matching double difference method as an estimation tool. All control variables were used as matching characteristic variables, based on the samples from 2006, and a one-to-one nearest neighbor matching method was used. Finally, 1036 samples were obtained for the experimental group and the control group. The Formula (1) was estimated using the matched samples, and the result is shown in the Regression (2). Clearly, the regression coefficient of the HTZ policy's virtual variables is still significantly positive at the level of $1 \%$, which also confirms the robustness of the above conclusions. 
Table 3. Robustness test.

\begin{tabular}{|c|c|c|c|c|c|c|}
\hline & (1) & (2) & (3) & (4) & (5) & (6) \\
\hline Variables & inno & inno & inno & inno & inno & inno \\
\hline HTZ & $\begin{array}{c}0.2175 * * * \\
(0.0249)\end{array}$ & $\begin{array}{c}0.0560 * * * \\
(0.0103)\end{array}$ & $\begin{array}{c}0.0725^{* * *} \\
(0.0133)\end{array}$ & $\begin{array}{c}-0.0039 \\
(0.0125)\end{array}$ & $\begin{array}{c}-0.0048 \\
(0.0123)\end{array}$ & $\begin{array}{c}-0.0169 \\
(0.0124)\end{array}$ \\
\hline innocity & & & $\begin{array}{c}0.0742 * * * \\
(0.0225)\end{array}$ & & & \\
\hline agglomeration & & & $\begin{array}{c}0.0609 * * * \\
(0.0119)\end{array}$ & & & \\
\hline HSR & & & $\begin{array}{c}0.0351 * * * \\
(0.0126)\end{array}$ & & & \\
\hline $\begin{array}{l}\text { Control } \\
\text { variable }\end{array}$ & $\mathrm{Y}$ & $\mathrm{Y}$ & $\mathrm{Y}$ & $\mathrm{Y}$ & $\mathrm{Y}$ & $\mathrm{Y}$ \\
\hline Time effect & $\mathrm{Y}$ & $\mathrm{Y}$ & $\mathrm{Y}$ & $\mathrm{Y}$ & $\mathrm{Y}$ & $\mathrm{Y}$ \\
\hline $\begin{array}{l}\text { Individual } \\
\text { effect }\end{array}$ & Y & $\mathrm{Y}$ & $\mathrm{Y}$ & $\mathrm{Y}$ & $\mathrm{Y}$ & $\mathrm{Y}$ \\
\hline Constant & $\begin{array}{c}2.4190 * * * \\
(0.2823)\end{array}$ & $\begin{array}{c}0.3841^{* * *} \\
(0.1250)\end{array}$ & $\begin{array}{c}2.2310^{* * *} \\
(0.2793)\end{array}$ & $\begin{array}{c}0.9324^{* * *} \\
(0.1501)\end{array}$ & $\begin{array}{c}0.9309 * * * \\
(0.1501)\end{array}$ & $\begin{array}{c}0.9111^{* * *} \\
(0.1504)\end{array}$ \\
\hline Observations & 2981 & 2067 & 2981 & 2981 & 2981 & 2981 \\
\hline R-squared & 0.5079 & 0.4068 & 0.5215 & 0.4066 & 0.4066 & 0.4070 \\
\hline $\begin{array}{l}\text { Number of } \\
\text { cities }\end{array}$ & 215 & 148 & 215 & 215 & 215 & 215 \\
\hline
\end{tabular}

Third, this paper needs to exclude the influence of other policy factors from the analysis results. At the urban level, the state has issued a series of targeted policies. Among them, the state's 2008 pilot policy for innovative cities is the most representative. Furthermore, in view of the weak economic and technological links and the disordered competition among cities, China began to outline a series of urban agglomerations to strengthen innovative links between cities and improve urban innovation. In terms of transportation infrastructure, the state actively promotes the high-speed railway, resulting in time-space compression between cities. This advantage can effectively promote the exchange of knowledge and technology and drive urban ecological innovation. Hence, researchers set a series of policy dummy variables, such as innovative city pilot (innocity), urban agglomeration planning (agglomeration) and high-speed rail (HSR), which are estimated by Formula (1); the results are shown in Regression (3). It is clear that the pilot policies of innovative cities, the planning policies of urban agglomerations, and the opening and operation of high-speed railways have a significant role in promoting urban ecological innovation. After controlling the influence of the three kinds of competitive policies mentioned earlier, HTZ construction still plays a significant role in promoting urban ecological innovation.

Finally, researchers randomize the policy impact: randomly selecting the time of policy occurrence and the experimental group, so as to conduct counterfactual analysis. More specifically, researchers randomly select the cities covered by each of the seven geographical regions of China: Southwest, Northwest, North, and South China are categorized as experimental groups, while East, Central, and Northeast China are control groups. It is assumed that the policy implementation years are 2009, 2010, and 2011. Based on the above settings, this paper constructs a double difference model for estimation, and the results are shown from Regressions (4)-(6) in Table 3. The three sets of regressions correspond to 2009, 2010, and 2011, respectively. Results show that the estimation coefficient of the HTZ policy's virtual variables has an absolute value of nearly zero 0 , thus failing to pass the significance test. It is evident that there is no systematic difference in the trend of urban ecological innovation level between the experimental group and the control group apart from the policy impact of HTZ construction, and that the estimation results are valid.

In summary, our robustness tests based on a variety of methods have confirmed the robustness of the baseline regression results. So, it can be seen that the construction of HTZs in China has indeed raised the urban ecological innovation level. 


\subsection{Heterogeneity Characteristics Test}

First, to test the validity of Hypothesis 2a (that is, to investigate the urban hierarchy heterogeneity of the impact of HTZ construction on ecological innovation), a virtual variable of city hierarchy (hierarchy) is created. The central city is assigned a value of 1 and the peripheral city a value of 0 , and these are substituted into Equation (2) for estimation. The results are shown in Regression (1) in Table 4. It is evident that the coefficient of the HTZ policy's cross multiplier and the virtual variable of city level is positive at the significance level of $1 \%$. This indicates that HTZ's promotion of ecological innovation is significantly stronger in the central city than the peripheral city, which is consistent with Hypothesis 2a. This may be because HTZ construction strengthens the policy depression effect of the central city, which is conducive to the concentration of urban innovation resources and plays a major role in promoting ecological innovation. In peripheral cities, however, scientific and technological innovation continues to focus on productive innovation aimed at expanding economic scale, and HTZ construction has a relatively weak driving effect on ecological innovation.

Table 4. Analysis of adjustment mechanism.

\begin{tabular}{|c|c|c|c|}
\hline & (1) & (2) & (3) \\
\hline Variables & inno & inno & inno \\
\hline HTZ & $\begin{array}{c}0.0442 * * * \\
(0.0159)\end{array}$ & $\begin{array}{c}0.0870 * * * \\
(0.0135)\end{array}$ & $\begin{array}{c}0.0858 * * * \\
(0.0134)\end{array}$ \\
\hline HTZ $\times$ hierarchy & $\begin{array}{c}0.1290 * * * \\
(0.0481)\end{array}$ & & \\
\hline $\mathrm{HTZ} \times$ education & & $\begin{array}{c}0.0903 \text { ** } \\
(0.0443)\end{array}$ & \\
\hline $\mathrm{HTZ} \times$ location & & & $\begin{array}{c}0.1253 * * * \\
(0.0231)\end{array}$ \\
\hline Control variable & Y & Y & $\mathrm{Y}$ \\
\hline Time effect & $\mathrm{Y}$ & Y & $\mathrm{Y}$ \\
\hline Individual effect & Y & Y & $\mathrm{Y}$ \\
\hline Constant & $\begin{array}{c}0.7667^{* * *} \\
(0.1484)\end{array}$ & $\begin{array}{c}0.8176^{* * *} \\
(0.1488)\end{array}$ & $\begin{array}{c}0.8155^{* * *} \\
(0.1487)\end{array}$ \\
\hline Observations & 2981 & 2981 & 2981 \\
\hline R-squared & 0.4235 & 0.4182 & 0.4188 \\
\hline
\end{tabular}

Second, to test Hypothesis $2 b$ (i.e., that the impact of HTZ construction on urban ecological innovation is characterized by heterogenous science and education resources), it is necessary to establish the virtual variable of urban science and education resource quality (education). As an important base for personnel training and scientific research activities, colleges and universities can provide appropriate resources for scientific and technological innovation. Thus, they are a key component in the development of an innovative economy. In 1995, the state launched the 211 Project, which serves to support universities in their discipline construction and improve their scientific research. Over the years, being selected to join the 211 Project has become an important indicator that attests to the level of science and education development in colleges and universities. Thus, dummy variables are created for the quality of urban science and education resources based on whether the city has the universities participating in the "211 Project" (an alliance of top-quality universities in China). Their presence is deemed an indication that the city has high-quality science and education resources, and it is assigned the value 1; if the opposite is true, the city it is assigned a value of 0 . We substitute the quality of science and education resources dummy variable and the HTZ policy dummy variable into Equation (2) for estimation, and the result is shown in Regression (2). It is evident that the estimated coefficient of the cross-product between HTZ policy and quality of science and education resources is positive at the $5 \%$ significance level. This indicates that the HTZ policy has a significantly 
stronger role in promoting ecological innovation in cities with higher quality of science and education resources than in cities with the opposite, thereby confirming Hypothesis $2 b$. This is mainly because the presence of such resources creates the necessary foundation for ecological innovation, and HTZ construction itself supports the integration of scientific, educational, and industrial resources related to ecological innovation. In this way, it forms an efficient, collaborative industry-university innovation research system that fosters urban ecological innovation.

Finally, to test Hypothesis 2c (i.e., examine the location heterogeneity of the impact of HTZ construction on ecological innovation), a regional dummy variable (location) is established, with a value of 1 assigned Eastern China and 0 to Central and Western China. The aforementioned disparity seen in the economic and technical development of the former and the later regions necessitates that we investigate the difference between HTZconstruction's ecological innovation effect in each of these regions. Thus, we created the cross-multiplication term of the HTZ policy and the regional dummy variable and put it into Equation (2) for estimation; the result is shown in Regression (3). It is evident that the estimated coefficient of the crossover term is positive at the $1 \%$ significance level. This result demonstrates that the HTZ construction has a significantly stronger role in promoting ecological innovation in the Eastern region than in the Central and Western ones. This is mainly because HTZ construction has reinforced the aforementioned geographical advantages and aided the accumulation of innovative elements in the Eastern region.

\subsection{Analysis of Intermediary Mechanism}

The foregoing results show that HTZ construction can foster improved urban ecological innovation. This may be due to the reasons mentioned in Hypothesis 3: the HTZ construction has a policy depression effect, which can attract high-quality talents and high-quality investment clusters, thereby promoting urban ecological innovation. This article will further examine these two mechanisms of change.

First, researchers examine the mediating effect of talent agglomeration. We refer to the practice of Li and Yang (2019) and use the proportion of urban science and education professionals in the total population to measure the level of talent concentration [23]. Based on this agglomeration index, Ender's Stata program is used to estimate the intermediary effect model shown in Formulas (1), (3) and (4). The results are shown in Table 5 from Regressions (1)-(3). Regression (1) gives the estimated results of the impact of HTZ construction on urban ecological innovation, and it is evident that the HTZ coefficient is positive under the significance level of $1 \%$. This indicates that HTZ construction have significantly promoted urban ecological innovation, which is consistent with the above conclusion. In Regression (2), the estimation coefficient for HTZ talent agglomeration is positive at the significance level of $5 \%$. This demonstrates that the HTZ policy has significantly promoted the gathering of high-quality talents in cities and provided the foundation of human capital necessary for urban ecological advancement. Regression (3) gives the estimated results of the national HTZ policy and talent agglomeration's impact on urban ecological innovation. The estimation coefficient of the latter is positive at the significance level of $1 \%$. Combined with the estimation result of Regression (2), it can be determined that the HTZ policy can promote urban talent agglomeration, so that it can significantly reinforce urban ecological innovation. Still, at 0.0054 , this mediating effect is relatively small and accounts for just 5.84\% of the total effect. Additionally, to assess whether the intermediary mechanism of talent agglomeration is robust, we conduct the Sobel and Bootstrap tests, and results all affirm the intermediary effect of talent agglomeration at a higher confidence level. After controlling the intermediary effect of urban talent agglomeration, the estimation coefficient of HTZ policy variables in Regression (3) is still positive at the significance level of $1 \%$. This indicates that HTZ construction can also promote urban ecological innovation, directly or indirectly.

Second, we test the intermediary effect of investment agglomeration. Referring to Li and Yang (2019), we use the ratio of urban fixed asset investment to urban administrative 
area to measure urban investment density, and estimate it based on the above intermediary effect model [23]. The results are shown from Regressions (4)-(6) in Table 5. Consistent with the previous analysis, the estimated coefficient of HTZ construction in Regression (4) is significantly positive at the level of $1 \%$. From Regression (5), it is evident that the coefficient of HTZ construction is positive at the significance level of $1 \%$. This indicates that HTZ construction has a policy depression effect and plays a significant role in promoting urban investment agglomeration. Regression (6) presents the estimated results of ecological innovation by national HTZ policy and investment agglomeration. Of these, the estimation coefficient of investment agglomeration to ecological innovation is positive at the significance level of $1 \%$, indicating that urban fixed asset investment has green and innovative attributes. This may create a financial context conducive to urban ecological innovation. Regression (6) shows the estimated results of HTZ construction and investment agglomeration's impact on urban ecological innovation. The estimation coefficient of investment agglomeration to ecological innovation is positive at the significance level of $1 \%$. This indicates that urban fixed asset investment has green and innovative attributes, which may establish a financial foundation that is conducive to urban ecological innovation. Combined with the results of Regression (5), one may ascertain that HTZ construction promotes the agglomeration of investment factors, thereby facilitating urban ecological advancement. The intermediary effect of urban investment agglomeration is 0.0528 , accounting for $56.57 \%$ of the total effect. It is evident that HTZ construction's agglomeration effect on urban fixed asset investment is the primary vehicle for urban ecological innovation. The results of Sobel and Bootstrap tests also confirm the intermediary mechanism of urban investment agglomeration. After controlling the intermediary effect of investment agglomeration, the estimation coefficient of urban ecological innovation in Regression (6) is still significantly positive. This indicates that urban investment agglomeration is a partial intermediary variable, and HTZ construction can promote urban ecological innovation directly or through other mechanisms.

Table 5. Analysis of intermediary mechanism.

\begin{tabular}{|c|c|c|c|c|c|c|}
\hline & (1) & (2) & (3) & (4) & (5) & (6) \\
\hline Variables & inno & talent & inno & inno & invest & inno \\
\hline HTZ & $\begin{array}{c}0.0933^{* * *} \\
(0.0131)\end{array}$ & $\begin{array}{l}0.0032^{* *} \\
(0.0013)\end{array}$ & $\begin{array}{c}0.0878^{* * *} \\
(0.0129)\end{array}$ & $\begin{array}{c}0.0933^{* * *} \\
(0.0131)\end{array}$ & $\begin{array}{c}0.0400^{* * *} \\
(0.0035)\end{array}$ & $\begin{array}{c}0.0405^{* * *} \\
(0.0126)\end{array}$ \\
\hline talent & & & $\begin{array}{c}1.7279 * * * \\
(0.1891)\end{array}$ & & & \\
\hline investment & & & & & & $\begin{array}{c}1.3202 \text { *** } \\
(0.0670)\end{array}$ \\
\hline $\begin{array}{l}\text { Control } \\
\text { variable }\end{array}$ & $\mathrm{Y}$ & $\mathrm{Y}$ & $\mathrm{Y}$ & $\mathrm{Y}$ & $\mathrm{Y}$ & $\mathrm{Y}$ \\
\hline Time effect & Y & $\mathrm{Y}$ & $\mathrm{Y}$ & $\mathrm{Y}$ & $\mathrm{Y}$ & $\mathrm{Y}$ \\
\hline Individual & $\mathrm{Y}$ & $\mathrm{Y}$ & $\mathrm{Y}$ & $\mathrm{Y}$ & $\mathrm{Y}$ & $\mathrm{Y}$ \\
\hline Constant & $\begin{array}{c}0.8544^{* * *} \\
(0.1652)\end{array}$ & $\begin{array}{c}0.3322^{* * *} \\
(0.0164)\end{array}$ & $\begin{array}{c}0.2804 \\
(0.1744)\end{array}$ & $\begin{array}{c}0.8576^{* * *} \\
(0.1653)\end{array}$ & $\begin{array}{c}0.3586^{* * *} \\
(0.0441)\end{array}$ & $\begin{array}{c}0.3841 \text { ** } \\
(0.1566)\end{array}$ \\
\hline Sobel test & \multicolumn{3}{|c|}{$0.0054(z=2.336, p=0.019)$} & \multicolumn{3}{|c|}{$0.0528(\mathrm{z}=9.883, p=0.000)$} \\
\hline $\begin{array}{l}\text { Bootstrap } \\
\text { test (ind_eff) }\end{array}$ & \multicolumn{3}{|c|}{$0.0054(z=2.45, p=0.014)$} & \multicolumn{3}{|c|}{$0.0528(\mathrm{z}=5.09, p=0.000)$} \\
\hline $\begin{array}{l}\text { Bootstrap } \\
\text { test (dir_eff) }\end{array}$ & \multicolumn{3}{|c|}{$0.0878(\mathrm{z}=4.57, p=0.000)$} & \multicolumn{3}{|c|}{$0.0405(z=2.42, p=0.015)$} \\
\hline $\begin{array}{l}\text { Mediating } \\
\text { effect } \\
\text { proportion }\end{array}$ & \multicolumn{3}{|c|}{$5.84 \%$} & \multicolumn{3}{|c|}{$56.57 \%$} \\
\hline Observations & 2981 & 2981 & 2981 & 2980 & 2980 & 2980 \\
\hline R-squared & 0.6373 & 0.8546 & 0.6480 & 0.6373 & 0.8201 & 0.6823 \\
\hline
\end{tabular}

This analysis demonstrates that HTZ construction can promote ecological innovation by enhancing the concentration of urban talent and investment. The sum of the mediation effects of these two mechanisms is 0.0582 , accounting for $62.38 \%$ of the total effect. It is 
evident that HTZ construction can promote urban ecological innovation largely because it agglomerates innovative elements, which may be conducive to urban ecological innovation. Thus, Hypothesis 3 has been confirmed.

\subsection{Spatial Mechanism Analysis}

When the government adopts preferential innovation and entrepreneurship policies, a policy depression is formed in a given city area. It serves to attract high-tech industries and innovative capital agglomeration. This raises the question of whether HTZs' policy depression effect will plunder and siphon the ecological innovation resources and elements in surrounding areas. To answer this question, we estimate the spatial double difference model shown in Formula (5), and the results are shown in Table 6. First, Regression (1) uses the neighboring weight matrix of the province in question and the area outside of it. The results show that the regression coefficients of policy dummy variables and spatial terms are both positive, and pass the significance level test of $5 \%$. This shows that HTZ construction will not only improve the ecological innovation in the city it is in, but have significant spillover effects on surrounding cities and other cities in the province, promoting ecological innovation there, too. Second, Regression (2) uses the intra-provincial correlation weight matrix, demonstrating that the regression coefficients of policy dummy variables and spatial terms are significantly positive at the level of $1 \%$. This shows that HTZ construction not only improves the ecological innovation level of the city, but has a significant innovation spillover effect on other cities in the province, promoting their ecological advancement, also. Finally, Regression (3) uses the correlation weight matrix of neighboring provinces, indicating that the regression coefficient of policy dummy variables is significantly positive, but the regression coefficient of spatial terms is significantly negative at the level of $5 \%$. This shows HTZ construction has a significant inhibitory effect on the ecological innovation of neighboring cities in other provinces. In summary, while HTZ construction enhances urban ecological innovation, it also has a significant spillover effect, which will foster ecological advancement in other provincial cities. This spillover effect is, however, limited to the inner cities of the province. In neighboring cities in other provinces, HTZ construction will significantly inhibit ecological innovation. Thus, Hypothesis 4 was only partially confirmed. As previously stated, cities are placed under the jurisdiction of the provincial government; those in the same province have formed cooperative relationships for innovation and cooperation under the unified planning and guidance of that government. However, under the promotion tournament mechanism of centralized political power, the developmental competition between provincial governments spreads to the city or even enterprise level. This results in a disorderly competition pattern in which cities in different provinces and regions rob each other of resources for technological innovation. Thus, HTZ construction's ecological innovation effect entails "cooperation within the province and competition outside the province" at the spatial level.

Table 6. Siphoning effect and spillover effect of HTZs.

\begin{tabular}{cccc}
\hline & $\mathbf{( 1 )}$ & $\mathbf{( 2 )}$ & $\mathbf{( 3 )}$ \\
\hline $\begin{array}{c}\text { Correlation Effect } \\
\text { Range }\end{array}$ & $\begin{array}{c}\text { Province-Related and } \\
\text { Outside the Province Cities }\end{array}$ & Province-Related & $\begin{array}{c}\text { Neighboring Cities } \\
\text { Outside the Province }\end{array}$ \\
\hline HTZ & $0.0941^{* * *}$ & $0.0937^{* * *}$ & $0.0900^{* * *}$ \\
W $\times$ HTZ & $(0.0131)$ & $(0.0131)$ & $(0.0131)$ \\
Control variable & $0.0077^{* *}$ & $0.0153^{* * *}$ & $-0.0363^{* *}$ \\
Time effect & $(0.0038)$ & $(0.0042)$ & $(0.0102)$ \\
Individual effect & $\mathrm{Y}$ & $\mathrm{Y}$ & $\mathrm{Y}$ \\
Constant & $\mathrm{Y}$ & $\mathrm{Y}$ & $\mathrm{Y}$ \\
$\mathrm{N}$ & $0.7971^{* * *}$ & $0.7783^{* * *}$ & $0.8118^{* * *}$ \\
R-squared & $(0.1488)$ & $(0.1486)$ & $(0.1483)$ \\
& 3010 & 3010 & 3010
\end{tabular}

Note: ${ }^{* * *} p<0.01,{ }^{* *} p<0.05$, and ${ }^{*} p<0.1$. Standard errors in parentheses. 


\section{Conclusions}

High-tech zones constitute an important policy measure for the transition to an innovative economy and serve as spaces for the nation to explore regional innovation development paths with Chinese characteristics. They are also important vehicles for implementing innovation-driven development strategy and promoting high-quality economic development. The HTZ is essentially a policy-guided high-tech industry cluster area. With the aid of national policy advantages that gather innovative resources and develop high-tech industries, it promotes the innovative development and sustainable development of the urban economy. To determine whether national HTZ construction can promote urban ecological innovation, this study used panel data from 215 Chinese cities spanning from 2003 to 2016. It empirically analyzed HTZ policy's impact on urban ecological innovation and the mechanisms of this influence. The main conclusions are as follows.

First, HTZ construction can effectively promote urban ecological innovation, and this ecological innovation effect has significant spatial heterogeneity. Moreover, HTZ construction is more impactful in promoting ecological innovation activities in core cities, cities in eastern regions, and cities with high-quality scientific and educational resources than they are in peripheral cities, cities in central and western regions and cities with sub-par scientific and educational resources. Thus, when formulating and promoting HTZ policy, we should adhere to the principle of adjusting measures to local conditions-fully accounting for the differences in economic and technological development between regions. It is also necessary to adopt diversified policies and measures to maximize the ecological innovation effect.

Second, the analysis of intermediary mechanisms showed that HTZ construction has a policy depression effect and factor agglomeration effect, which are key contributors to urban ecological advancement. Specifically, HTZ construction, and the accompanying preferential policies, foster the agglomeration of urban innovation factors (including highquality talents and fixed asset investment), which promotes urban ecological advancement. Moreover, HTZ construction's investment agglomeration effect is the chief mechanism through which urban ecological innovation is enhanced. Thus, in the construction process, we must prioritize the need to attract high-quality innovative capital and superior talentsthe presence of which is conducive to urban ecological innovation. For their part, cities without HTZs should gather innovative elements by formulating preferential policies and optimizing the business environment to promote urban ecological innovation.

Third, the spatial effect analysis showed that HTZ construction's ecological innovation effect is marked by "cooperation within the province and competition outside the province". Specifically, HTZ construction not only promotes ecological innovation in their locality, it has a significant spillover effect on the ecology of other provincial cities may also bolster ecological innovation therein. Yet, the analysis also found that the HTZ construction has a significant siphoning effect on neighboring cities outside the province: suppressing the ecological innovation in those locales. Accordingly, all regions should strengthen inter-provincial ecological innovation cooperation by establishing cooperation parks and collaborative innovation relations. It is necessary to support and improve inter-provincial transportation and information, as well as other infrastructure. This may improve the inter-provincial innovation and cooperation network and maximize the HTZ construction driving effect both in urban spaces and beyond.

Finally, it is necessary to discuss study implications. First, this paper does not investigate the micro-mechanisms of the impact of HTZ construction on urban ecological innovation. Enterprises are the micro-main body of innovation activities, but, due data limitations, this paper does not investigate the micro-ecological innovation effect HTZ construction. Second, this paper discusses the spatial effect of HTZ construction, and observes that the ecological innovation effect has the spatial characteristics of "cooperation within the province and competition outside the province", yet it does not provide another case study to illustrate this mechanism. 
Author Contributions: Conceptualization, S.Y. and W.L.; methodology, S.Y.; writing一original draft preparation, S.Y.; writing-review and editing, W.L. and Z.Z.; supervision, W.L.; funding acquisition, S.Y. All authors have read and agreed to the published version of the manuscript.

Funding: This research was funded by the Special Research Project on Clean Government Construction of Jilin University, grant number 2021LZY010, and the Special Research Project on Northeast Revitalization and Development of Jilin University, grant number 20ZXZ11.

Institutional Review Board Statement: Not applicable.

Informed Consent Statement: Not applicable.

Data Availability Statement: Data presented in this work are available on request from the first author.

Conflicts of Interest: The authors declare no conflict of interest.

\section{References}

1. Popp, D.; Newell, R.G.; Jaffe, A.B. Energy, the environment, and technological change. Handb. Econ. Innov. $2010,2,873-937$.

2. Barbieri, N.; Ghisetti, C.; Gilli, M.; Marin, G.; Nicolli, F. A Survey of the Literature on Environmental Innovation Based on Main Path Analysis. J. Econ. Surv. 2016, 30, 596-623. [CrossRef]

3. Braun, E.; Wield, D. Regulation as a means for the social control of technology. Technol. Anal. Strateg. Manag. 1994, 6, $259-272$. [CrossRef]

4. James, P. The sustainability circle: A new tool for product development and design. J. Sustain. Prod. Des. 1997, 2, 52-57.

5. Latupeirissa, G.; Adhariani, D. External and internal economic impacts of eco-innovation and the role of political connections: A sustainability narrative from an emerging market. J. Clean. Prod. 2020, 258, 120579. [CrossRef]

6. Barrios, S.; Bertinelli, L.; Strobl, E. Coagglomeration and spillovers. Reg. Sci. Urban Econ. 2006, 36, 467-481. [CrossRef]

7. Zhuang, L.; Ye, C. Changing imbalance: Spatial production of national high-tech industrial development zones in China (1988-2018). Land Use Policy 2020, 94, 104512. [CrossRef]

8. Goetz, S.J.; Rupasingha, A. High-Tech Firm Clustering: Implications for Rural Areas. Am. J. Agric. Econ. 2002, 84, 1229-1236. [CrossRef]

9. Corrocher, N.; Lamperti, F.; Mavilia, R. Do science parks sustain or trigger innovation? Empirical evidence from Italy. Technol. Forecast. Soc. Chang. 2019, 147, 140-151. [CrossRef]

10. Xie, K.; Song, Y.; Zhang, W.; Hao, J.; Liu, Z.; Chen, Y. Technological entrepreneurship in science parks: A case study of Wuhan Donghu High-Tech Zone. Technol. Forecast. Soc. Chang. 2018, 135, 156-168. [CrossRef]

11. Li, Y.; Wang, X. Innovation in suburban development zones: Evidence from Nanjing, China. Growth Chang. 2018, 50, 114-129. [CrossRef]

12. Albahari, A.; Pérez-Canto, S.; Barge-Gil, A.; Modrego, A. Technology Parks versus Science Parks: Does the university make the difference? Technol. Forecast. Soc. Chang. 2017, 116, 13-28. [CrossRef]

13. Fukugawa, N. Science parks in Japan and their value-added contributions to new technology-based firms. Int. J. Ind. Organ. 2006, 24, 381-400. [CrossRef]

14. Guadix, J.; Carrillo-Castrillo, J.; Onieva, L.; Navascués, J. Success variables in science and technology parks. J. Bus. Res. 2016, 69, 4870-4875. [CrossRef]

15. Henriques, I.C.; Sobreiro, V.A.; Kimura, H. Science and technology park: Future challenges. Technol. Soc. 2018, 53, 144-160. [CrossRef]

16. Wang, J. The economic impact of Special Economic Zones: Evidence from Chinese municipalities. J. Dev. Econ. 2013, 101, 133-147. [CrossRef]

17. Zheng, S.; Li, Z. Pilot governance and the rise of China's innovation. China Econ. Rev. 2020, 63, 101521. [CrossRef]

18. Bai, X.-J.; Yan, W.-K.; Chiu, Y.-H. Performance evaluation of China's Hi-tech zones in the post financial crisis era-Analysis based on the dynamic network SBM model. China Econ. Rev. 2015, 34, 122-134. [CrossRef]

19. Yang, F.; Guo, G. Fuzzy comprehensive evaluation of innovation capability of Chinese national high-tech zone based on entropy weight-Taking the northern coastal comprehensive economic zone as an example. J. Intell. Fuzzy Syst. 2020, 38, 7857-7864. [CrossRef]

20. Cao, C. Zhongguancun and China's High-Tech Parks in Transition "Growing Pains" or "Premature Senility". Asian Surv. 2004, 44, 647-668. [CrossRef]

21. Wang, Q.; Yang, R.; Zhao, R.; Wang, C. Does State-level Upgrade of High-tech Zones Promote Urban Innovation Efficiency: Evidence from China. Sustainability 2019, 11, 6071. [CrossRef]

22. Yang, C.H.; Motohashi, K.; Chen, J.R. Are new technology-based firms located on science parks really more innovative? Res. Policy 2009, 38, 77-85. [CrossRef]

23. Li, Z.; Yang, S. Can National High-Tech Zones Raise Urban Innovation Level? South China J. Econ. 2019, $12,49-67$. 
24. Vásquez-Urriago, Á.R.; Barge-Gil, A.; Rico, M.A. Science and Technology Parks and cooperation for innovation: Empirical evidence from Spain. Res. Policy 2016, 45, 137-147. [CrossRef]

25. Zhao, Y.; He, D. An Empirical Study on the Utilization Efficiency of Innovation Resources in Intelligent Cities. J. China Soft Sci. 2009, 10, 109-116.

26. Teng, T.; Zhang, Y.; Si, Y.; Chen, J.; Cao, X. Government support and firm innovation performance in Chinese science and technology parks: The perspective of firm and sub-park heterogeneity. Growth Chang. 2020, 51, 749-770. [CrossRef]

27. Lai, H.-C.; Shyu, J.Z. A comparison of innovation capacity at science parks across the Taiwan Strait: The case of Zhangjiang High-Tech Park and Hsinchu Science-based Industrial Park. Technovation 2005, 25, 805-813. [CrossRef]

28. Autor, D.H. Outsourcing at Will: The Contribution of Unjust Dismissal Doctrine to the Growth of Employment Out-sourcing. J. Labor Econ. 2003, 21, 1-23. [CrossRef]

29. Bertrand, M.; Mullainathan, S. Enjoying the Quiet Life? Corporate Governance and Managerial Preferences. J. Political Econ. 2003, 111, 1043-1075. [CrossRef]

30. Baron, R.M.; Kenny, D.A. The moderator-mediator variable distinction in social psychological research: Conceptual, strategic, and statistical considerations. J. Personal. Soc. Psychol. 1986, 51, 1173. [CrossRef]

31. Delgado, M.S.; Florax, R.J. Difference-in-differences techniques for spatial data: Local autocorrelation and spatial interaction. Econ. Lett. 2015, 137, 123-126. [CrossRef]

32. Paliska, D.; Fabjan, D.; Vodopivec, R.; Drobne, S. The impact of the construction of motorways and expressways on housing prices in north-east Slovenia. Géod. Vestn. 2018, 62, 218-234. [CrossRef]

33. Hojnik, J.; Ruzzier, M. The driving forces of process eco-innovation and its impact on Performance: Insights from Slovenia. J. Clean. Prod. 2016, 133, 812-825. [CrossRef]

34. Przychodzen, J.; Przychodzen, W. Relationships between eco-innovation and financial performance-Evidence from publicly traded companies in Poland and Hungary. J. Clean. Prod. 2015, 90, 253-263. [CrossRef]

35. Kesidou, E.; Wu, L. Stringency of environmental regulation and eco-innovation: Evidence from the eleventh Five-Year Plan and green patents. Econ. Lett. 2020, 190, 109090. [CrossRef]

36. Cuerva, M.C.; Triguero, A.; Córcoles, D. Drivers of green and non-green innovation: Empirical evidence in Low-Tech SMEs. J. Clean. Prod. 2014, 68, 104-113. [CrossRef]

37. Girma, S.; Gong, Y.; Görg, H. What Determines Innovation Activity in Chinese State-owned Enterprises? The Role of Foreign Direct Investment. World Dev. 2009, 37, 866-873. [CrossRef]

38. Earl, M. Knowledge Management Strategies: Toward a Taxonomy. J. Manag. Inf. Syst. 2001, 18, $215-242$.

39. Wang, X.; Feng, Y. The effects of National High-tech Industrial Development Zones on economic development and environmental pollution in China during 2003-2018. Environ. Sci. Pollut. Res. 2021, 28, 1097-1107. [CrossRef] [PubMed] 